Review Article

\title{
A Visual Analysis of Frontiers and Dynamic Tendencies for Humanitarian Logistics
}

\author{
Shaochuan Fu $\mathbb{D}^{D}$, Xuehua Ji $\mathbb{D}^{D}$, Changxiang Lu $(\mathbb{D}$, and Shucheng Fan \\ School of Economics and Management, Beijing Jiaotong University, Beijing 100000, China \\ Correspondence should be addressed to Xuehua Ji; 20113037@bjtu.edu.cn
}

Received 13 January 2021; Revised 11 July 2021; Accepted 9 August 2021; Published 20 August 2021

Academic Editor: Neale R. Smith

Copyright (C) 2021 Shaochuan Fu et al. This is an open access article distributed under the Creative Commons Attribution License, which permits unrestricted use, distribution, and reproduction in any medium, provided the original work is properly cited.

Under the background of regular epidemic prevention and control, the frontiers and prospects of humanitarian logistics (HL) have substantial value in enhancing emergency capacity. Taking the relevant articles collected in Web of Science and Scopus databases as the research object, this study discusses the basic characteristics, hot topics, and the potential directions of HL, using the bibliometric analysis and statistical analysis methods. Results show that the number of articles presents an overall increase with fluctuation. The major driving force of HL research is from the USA and China. Although a certain cooperation size among authors has been formed, close contact among research teams from different institutions in different countries is lacking. In addition, the four main topics of HL are highlighted through the "co-occurrence" analysis of keywords by VOSviewer. Further research directions and suggestions can be identified under the analysis of each topic and the knowledge map of CiteSpace. It is expected that results will provide a theoretical reference to scholars when identifying innovative ideas in this field.

\section{Introduction}

Emergency events, which include sudden, abrupt and natural, a natural and slow onset, the sudden man-made onset, or the slow man-made onset (Van Wassenhove [1]), are the result of the ecological breakdown in the relation between man and environment. In fact, every year, an enormous number of people suffer from the effect of emergency events. In particular, a sudden outbreak of infectious disease, which had exerted serious influences on human life and socioeconomic development, had swept across the world in 2020. As of 26 June 2021, 3909491 individuals died all over the world, and more than 180 million people were infected by COVID-19, according to the data issued by the Center for Systems Science and Engineering at Johns Hopkins University [2]. This phenomenology highlights the importance of humanitarian logistics (HL), which is defined as the process of planning, implementing, and controlling flow, as well as the effective storage of goods (Altay and Green [3]).

Based on the pursuit of getting humanitarian response as quickly as possible, the role of HL has developed into one that can bring timely and necessary reliefs to the impacted areas and has great importance in dealing with emergency events and alleviating the suffering individuals. As early as the 1970s, the problem of an emergency model in the emergency management of natural disaster was explored, while the systematic study of HL in China began after the SARS epidemic in 2003. Recently, much work has been done on the topic of HL, which can be attested by the following analysis of year-wise publication trends. However, the reviews show that (1) while the existing studies provide an indepth understanding of subaspects of HL, most of them have focused on individual emergency phases; (2) these studies are rather isolated, and neither do they take a holistic perspective on the matter of HL nor consider its prospects. Hence, it is valuable to conduct a consistent and in-depth study on HL from the perspective of sustainable development.

To display the structured knowledge on HL, based on a systematic analysis of the academic literature on HL from 2011 to 2020, the exploratory-descriptive research topics and tendencies of HL will be revealed, through the statistical analysis and bibliometric analysis methodologies. The following questions are gradually answered: 
(i) RQ1: what are the characteristics of humanitarian logistics publications?

(ii) RQ2: what is the intellectual structure of various authors, institutions, references, countries, and journals in this field?

(iii) RQ3: what are the hot topics in the field of humanitarian logistics?

(iv) RQ4: what will be the potential research directions of humanitarian logistics in the near future?

The key findings of this paper will not only help scholars to scrutinize the evolving frontiers and research topics of HL but also outline a better comprehension and vital implications for practitioners. The novel contributions of this article are as follows:

(1) As it has been mentioned, most scholars study the improving approaches or strategies of HL from the micro-level, while this article draws up a more comprehensive structure of HL, which can be viewed from a macro-perspective.

(2) The novelty of this study lies in the fact that it establishes the academic basis for the important practice of HL and outlines vividly the intellectual structure and status quo of HL.

(3) The identification of hot points and potential research directions of HL throughout its different periods is proposed by using the VOSviewer and CiteSpace. It contributes to making some opinions and suggestions on HL.

The remainder of this paper is organized as follows. The next section describes the critical methods and the overall process of data searching. Section 3 discusses the basic characteristics of humanitarian logistics literature. In Section 4 , the hot topics of this field are proposed and outlined. Section 5 aims to address the dynamic frontiers and specific research directions of humanitarian logistics. In Section 6, some conclusions and suggestions are given.

\section{Methods and Data Sources}

2.1. Methods and Analytical Tools. The structure of this paper allows an organized way to explore the potential topics of $\mathrm{HL}$, through methods such as statistical analysis and bibliometric analysis. Statistical analysis plays a significant role in exploring and understanding the research theme, when the bibliographic data are large and difficult to analyze objectively. Meanwhile, to reveal the frontiers and dynamic tendency of HL precisely and visually, bibliometric analysis is also applied, which is an established method of scientific inquiry with applications in many research fields (Ellegaard and Wallin [4]). It can be conducive to using mathematical statistics to look for some innovative ideas (Pritchard [5]).

Compared with other visualization software, VOSviewer and CiteSpace can dig into the HL literature context more deeply. CiteSpace, developed by Chaomei Chan at Drexel University (US), is a popular information visualization software application using its co-citation analysis, cooperation analysis, and other functions to explain the burst trends and patterns in the literature (Chen et al. [6]). CiteSpace can be used to examine and analyze variables in the form of nodes, by which we can get the hotspots and pivotal points in specific domains (Cui et al. [7]). VOSviewer is a powerful visualization software application with the functions of "co-occurrence" network clustering and density analysis (Van Eck and Waltman [8]). Co-occurrence analysis is defined as the frequency of two articles cited together by other articles (Pilkington and Meredith [9]). This paper uses it to provide the easy-to-interpret clusters of keywords in $\mathrm{HL}$ literature.

2.2. Data Sources and Research Process. Web of Science (WoS) and Scopus are the platforms that provide the statistical literature information now and before, which are useful to map the state-of-the-art design of HL. Archambault et al. [10] compared the bibliometric data of WoS and Scopus and concluded that these databases offer robust tools for evaluating science. Therefore, we choose literature on WoS and Scopus as the data source instead of the traditional literature search of some journals. Meanwhile, according to the discrete law of Bradford literature, many articles in a certain research field are concentrated in the core journals. This paper restricts the search to the years 2011-2020 in the document types of articles, which use multiple disciplines in either the humanitarian modeling, logistics techniques, or solution methodologies.

Based on the previous papers and expert's views, this article follows the process of literature collection as applied by Seuring et al. [11]; four search strings are advised to ensure the coverage of related articles, and the strings are built with a combination of keywords, for example, (1) humanitarian=(("humanitarian logistics") OR ("humanitarian emergency") OR ("humanitarian logistics optimization model") OR ("humanitarian logistics optimization algorithms") OR ("humanitarian")) AND (2) emergencies $=(($ "emergency logistics") OR ("emergency logistics optimization model”) OR (“emergencies") OR ("emergency logistics technologies") OR ("emergency logistics optimization algorithms") OR ("emergency evacuation") OR ("emergency logistics management systems") OR ("emergency material scheduling")) AND (3) supply chain=(("supply chain") OR ("emergency supply chain”) OR ("emergency supply chain management") OR ("disaster supply chain") OR ("supply chain risk")) AND (4) others=(("crisis") OR (“disaster mutual assistance”) OR ("disaster response”) OR (“disaster") OR (“incident”)).

Given the broad search terms, to ensure the accuracy of the collected reviews on HL, the title, abstract, keywords, and other information wherever required are read extensively, and articles that are irrelevant to research themes are removed. The repetitive and irrelevant records are deleted by the means of NoteExpress and Excel tools, and 476 articles are finally retained and downloaded through a laborious process of manually checking and rechecking terms. The steps of filtering articles and analysis strategies are described in Figure 1. 


\section{Basic Characteristics Analysis of Humanitarian Logistics}

3.1. Year-Wise Publication Trend Analysis. According to the bibliometrics theory, the chronological statistics of documents reflect the development stage of HL. Articles included in the search published per year in scientific journals with peer review are shown in Figure 2. The number of publications shows a floating growth trend throughout different periods, which is consistent with the general trend in the academic field of HL. According to the difference in the curve growth rate, the year-wise publication tendency can be divided into two stages. The first stage is 2011-2016, where it shows a slowly rising trend, showing that this stage is the initial one. Among them, the number of articles issued was as high as 43 in 2016. This is related to the fact that HL has been recognized and discussed by academia. The next stage is 2017-2020, where the annual publication numbers are just a steady upward state, explaining that this stage is the growth stage. The maximum number of literature was 123 in 2020, and it may be due to the impact of COVID-19 and the related policies of HL.

3.2. Analysis of Most Influential Authors and Countries. As the main body of HL research, the author's appearance frequency and cooperation network are the crucial indicators. After analyzing the relevant data by the bibliometric map and statistical analysis methods, Table 1 is constructed. It reveals that Gunasekaran A. and Dubey R., Pedraza-Martinez A. J. and Van Wassenhove L. N., and Comes T. and Lauras M. have a good collaboration relationship. Furthermore, since the co-cited analysis is contributed to digging out the important information on articles (Pilkington and Meredith [9]), CiteSpace visual software is applied to explore the network of co-cited authors.

Figure 3 finds that $N$, density, modularity $Q$ (simplified as $Q$ ), and weighted mean silhouette (noted as $S$ ), respectively, are $499,0.0116,0.6245$, and 0.8542 . It is generally believed that $Q$ is bigger than 0.3 , indicating that the formation of community structure is more significant; $S$ is bigger than 0.5 , showing that the clustering effect is more reasonable, and when it is equal to 0.7 , it is highly concentrated (Chen et al. [12]). This result not only has an obvious community structure but also has good reliability of clustering effect. The higher an author's citation is, the bigger its node will be. Authors such as Balcik B., Altay N., and Van Wassenhove L. N. have higher citation frequencies, followed by Ozdamar L. and Sheu J. B., which are 207, 152, and 147. Although several core teams have gradually formed, the overall cooperation network of authors is relatively fragmented.

As illustrated in Table 1, from 2011 to 2020, China has the largest count with 135, followed by the USA, England, Iran, and France, which are 129, 57, 53, and 43 in the period. Although the USA ranks 2 nd in regard to the number of frequencies, it is the highest in terms of the centrality value (0.7), indicating that American scholars have relatively closer collaboration with researchers in other countries. Moreover, the USA and China and England and France have achieved a certain partnership. On the whole, some research teams have acquired academic achievement, but the cooperative network of authors and countries shows a "partial concentration and overall dispersion" trend. While learning the outstanding theories of HL from China and the USA, teams from different countries may need to strengthen contact and cooperation.

3.3. Analysis of Top Contributing Institutions. As the backbone of a research field, the contribution of institutions could be further understood. The cooperation mapping of important institutions is displayed in Figure 4 . The nodes represent institutions and the links between nodes express the partnership among institutions. The prolific institutions, such as Univ Tehran, Hanken Sch Econ, INSEAD, Iran Univ Sci and Technol, and Islamic Azad Univ, have contributed more articles in the HL field. Cooperation characteristics of regional institutions can be seen. For example, Shanghai Maritime Univ and Tongji Univ are the linked relationship, showing that they have a long-term partnership. In short, colleges and universities are in a dominant position with strong scientific ability and academic atmosphere. Although each institution has formed a certain research result, the cooperation among cross-regional, cross-national institutions is not relatively concentrated. If the institutional cooperation is further enhanced, it will promote the highquality development of HL.

3.4. Analysis of Outstanding Journals. The network of cocited journals is presented in Figure 5, where $N$, density, $S$, and $Q$ are 521, 0.0121, 0.8157, and 0.5916, respectively, revealing good reliability of the clustering effect. Because larger nodes illustrate higher citation frequencies, EUR J OPER RES, INT J PROD ECON, ANN OPER RES, and J OPER RES SOC have been the major platform for this theme. For instance, EUR J OPER RES, which has an average of 329 citations, is the most cited journal. Besides, sixteen journals have more than one hundred counts.

3.5. Analysis of Contributing References. It is noteworthy that the effort of different references of HL is conducive to the foundations on which measures are built for future work. The co-cited literature network map is constructed in Figure 6, the results of which present that the studies of Tofighi S (2016), Ozdamar L (2015), Gaunhye A M (2012), and Najafi M (2013) are the outstanding documents on HL research. Among them, Tofighi S (2016) is the most cited, whose reference received an average of 45 counts. As regards the centrality values, Balcik B (2010) is in the highest place with a centrality value of 0.13 , followed by Ozdamar (2012) and Day J M (2014). It means that previous literature reviews have formed a solid foundation and advanced the research process of HL. 


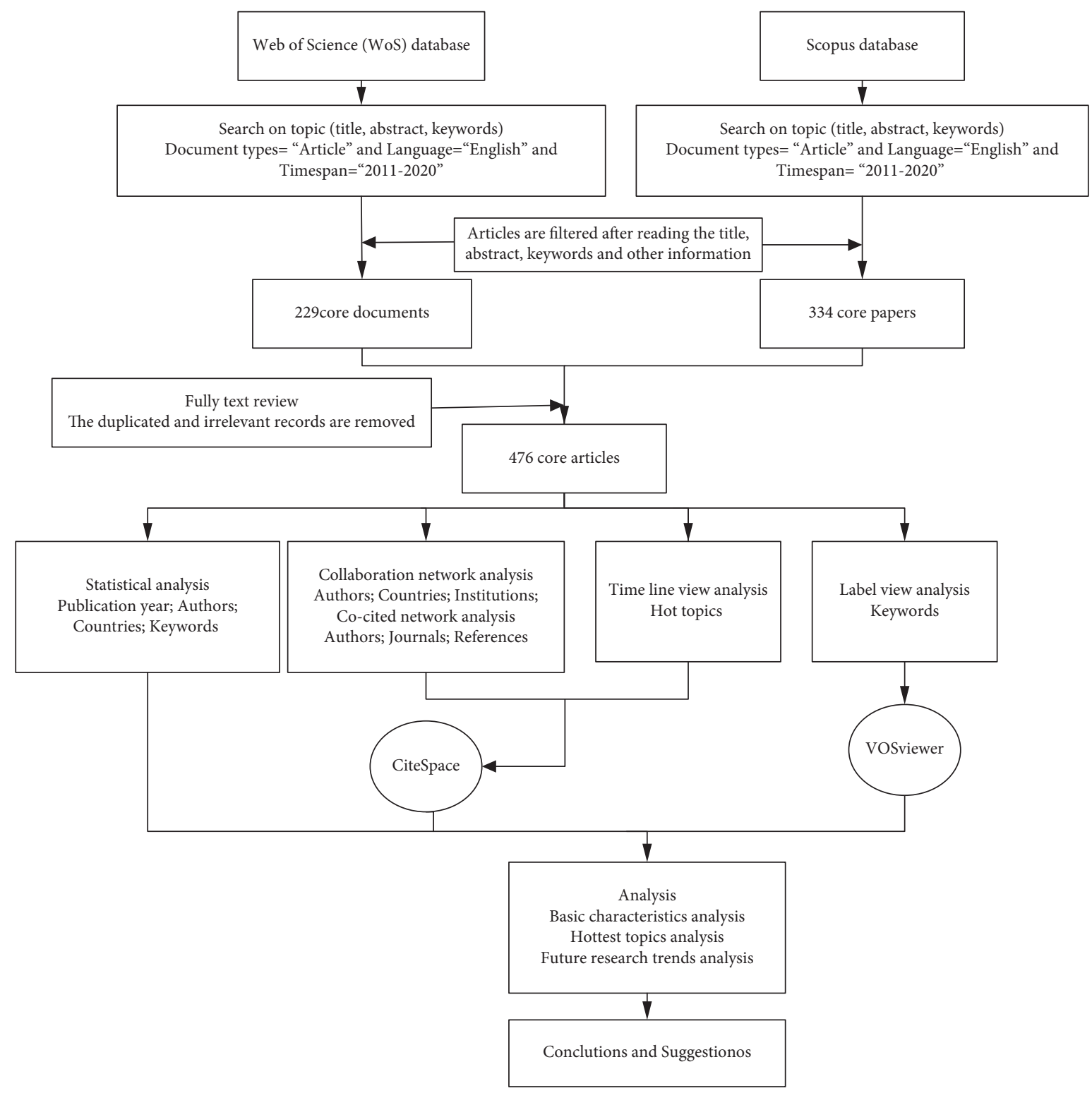

FIgURE 1: Flowchart of study selection and analysis strategy.

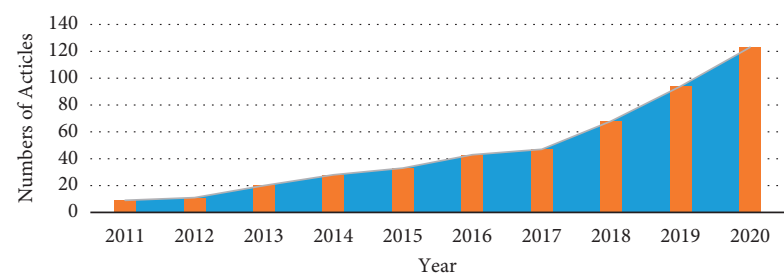

Figure 2: Number of articles per year.

\section{Hot Topic Analysis of Humanitarian Logistics}

Each article contains many keywords, and the activities of this field can be reflected by the growth of keywords (Cobo et al. [13]). Co-occurrence analysis is used to explore the dynamic evolution of a specific domain by evaluating the frequency of pairs of keywords or noun phrases appearing in the whole body
TABLE 1: Top eight contributing authors and countries.

\begin{tabular}{lccccc}
\hline Rank & Authors & Count & Rank & Countries & Count \\
\hline 1 & Van Wassenhove & 12 & 1 & China & 135 \\
2 & Dubey & 10 & 2 & USA & 129 \\
3 & Gunasekaran & 8 & 3 & England & 57 \\
4 & Bozorgi-Amiri & 7 & 4 & Iran & 53 \\
5 & Pedraza-Martinez & 7 & 5 & France & 43 \\
6 & Kovacs & 7 & 6 & Australia & 25 \\
7 & Lauras & 7 & 7 & India & 22 \\
8 & Comes & 6 & 8 & Turkey & 19 \\
\hline
\end{tabular}

of literature (Zhu et al. [14]). After we remove and merge meaningless and similar keywords, VOSviewer is used to make the visualization map of core keywords in Figure 7.

The more important an element is, the bigger its label will be, and the greater volume its associated circle will have (Garcia-Lillo et al. [15]). The label volume of "Humanitarian 


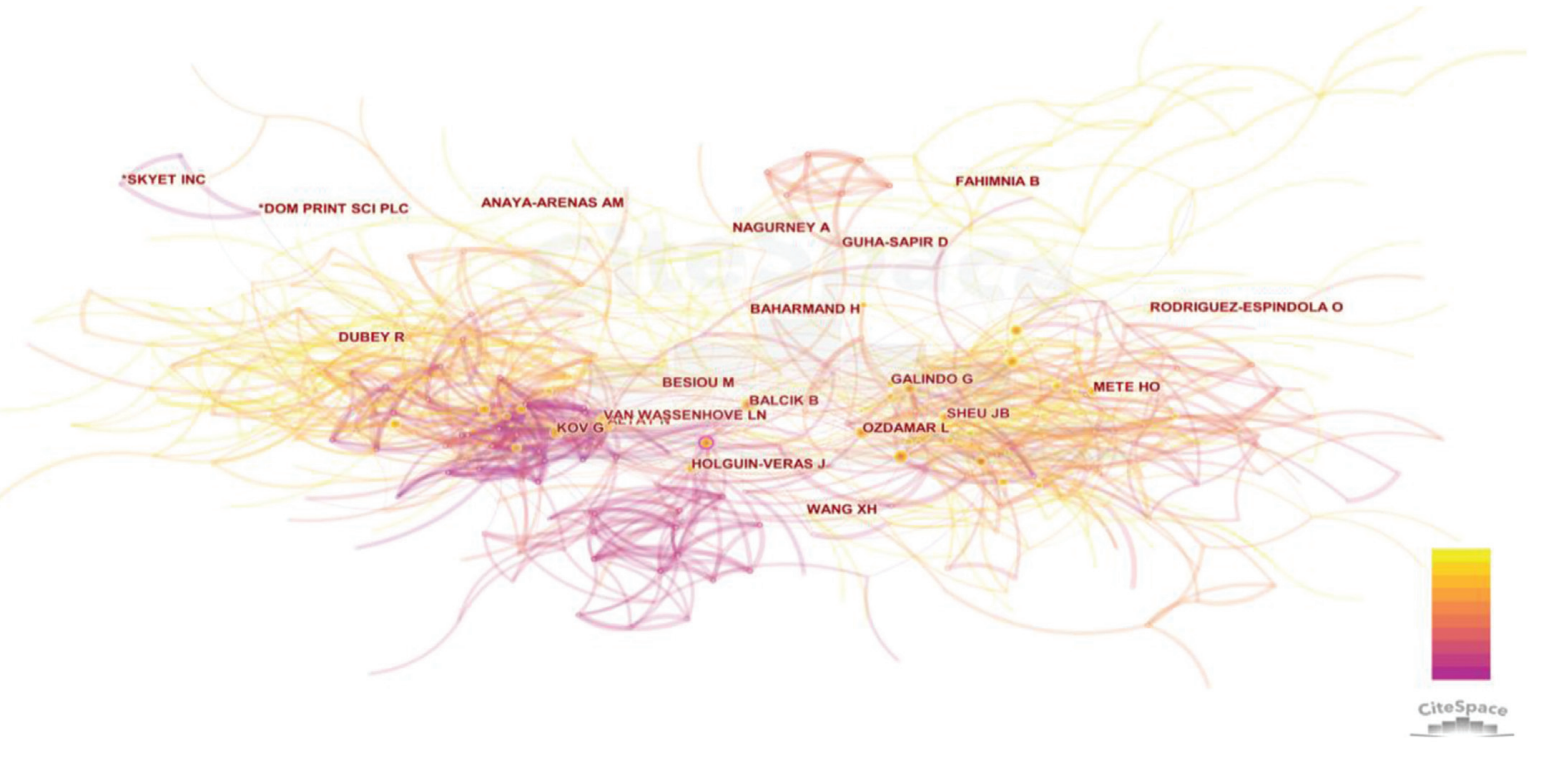

FIgURE 3: Network of co-cited authors.

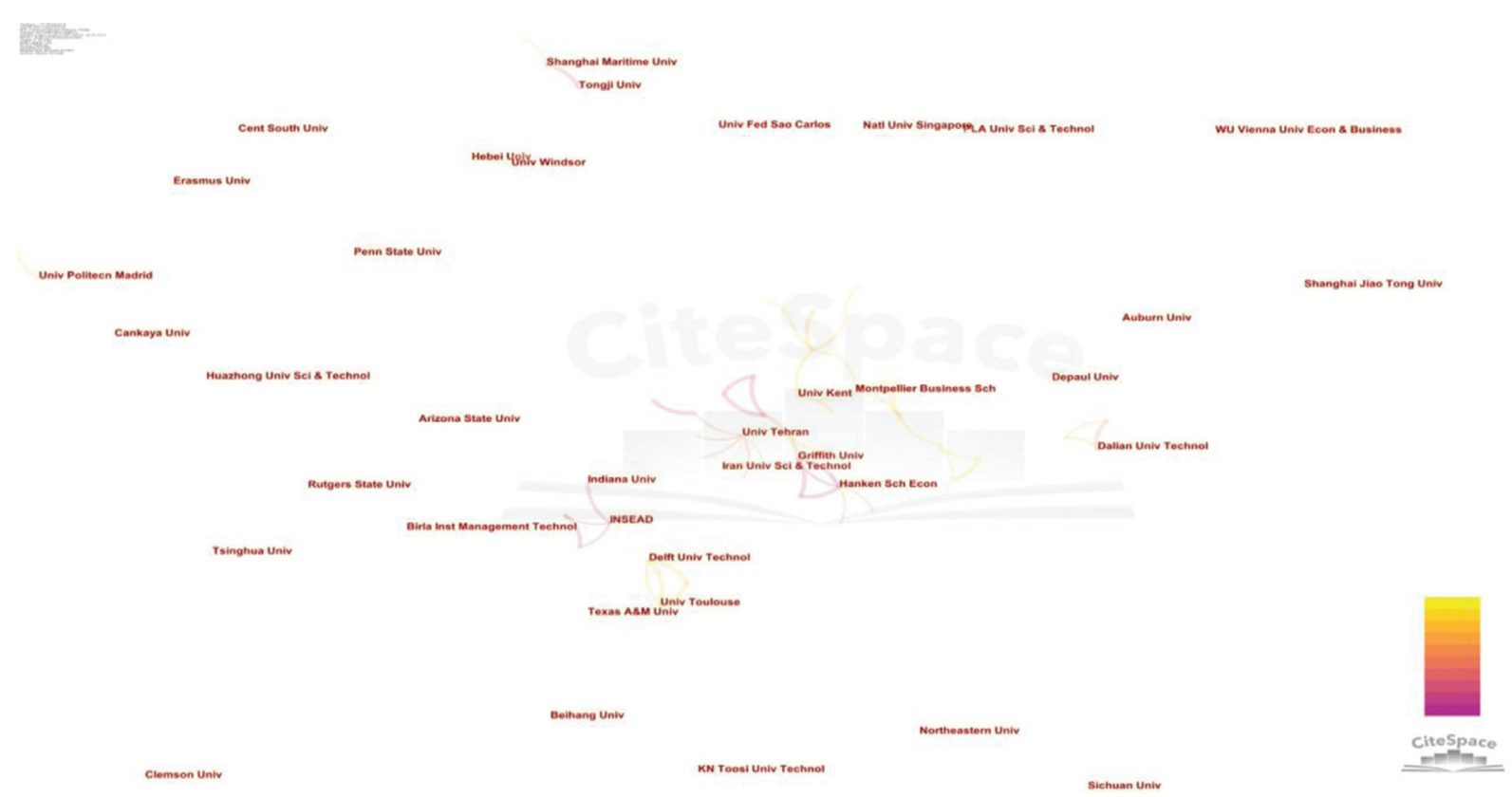

FIGURE 4: Network of important institutions.

logistics, Logistics, Optimization, Facility location, and Supply chain management" is bigger, and it shows that the frequency of those keywords is higher, which belongs to the hot problem in this field. Scholars consider the contents involving "The basic theory of HL, Emergency facilities location, Reverse emergency management, Technological innovation application, the collaborative system of HL, Multi-objective or robust optimization, Mathematic algorithms, etc." (Zhao et al. and Tofighi et al. [16, 17]). Furthermore, the nodes of "Logistics, Simulation, Supply chain management, and Emergency" are closer to the central circle, indicating that they are of greater importance and have a close relationship with HL. As we observe, since the same color of the keywords indicate that they have similar research directions, the nodes such as "Optimization, Algorithm, Reliability, Evacuation, etc." belong to the same cluster of the research topic.

Based on the analysis of hot keyword label view of HL, in the proposed categorization, we consider four major aspects: (i) factors affecting humanitarian performance, (ii) mathematical models and methodologies, (iii) humanitarian supply chain, and (iv) applied techniques and means. 


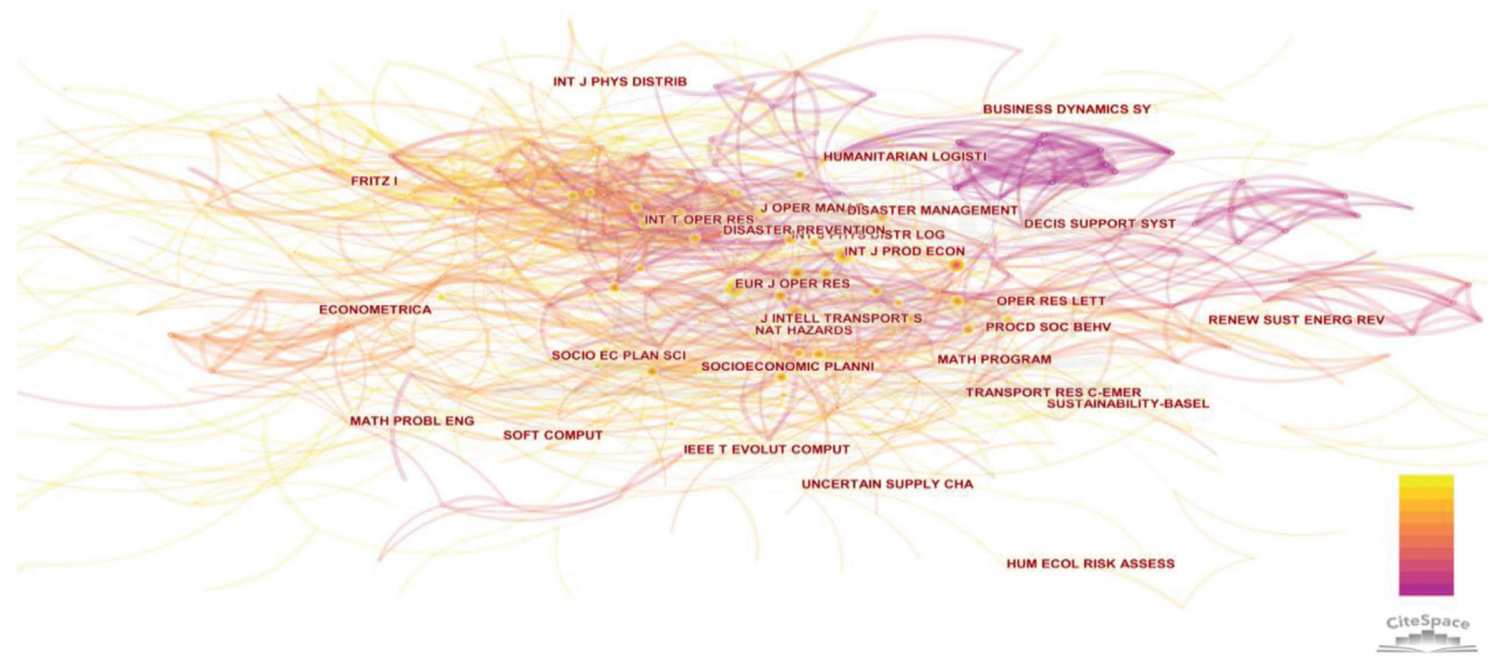

FIgURE 5: Network of co-cited journals.

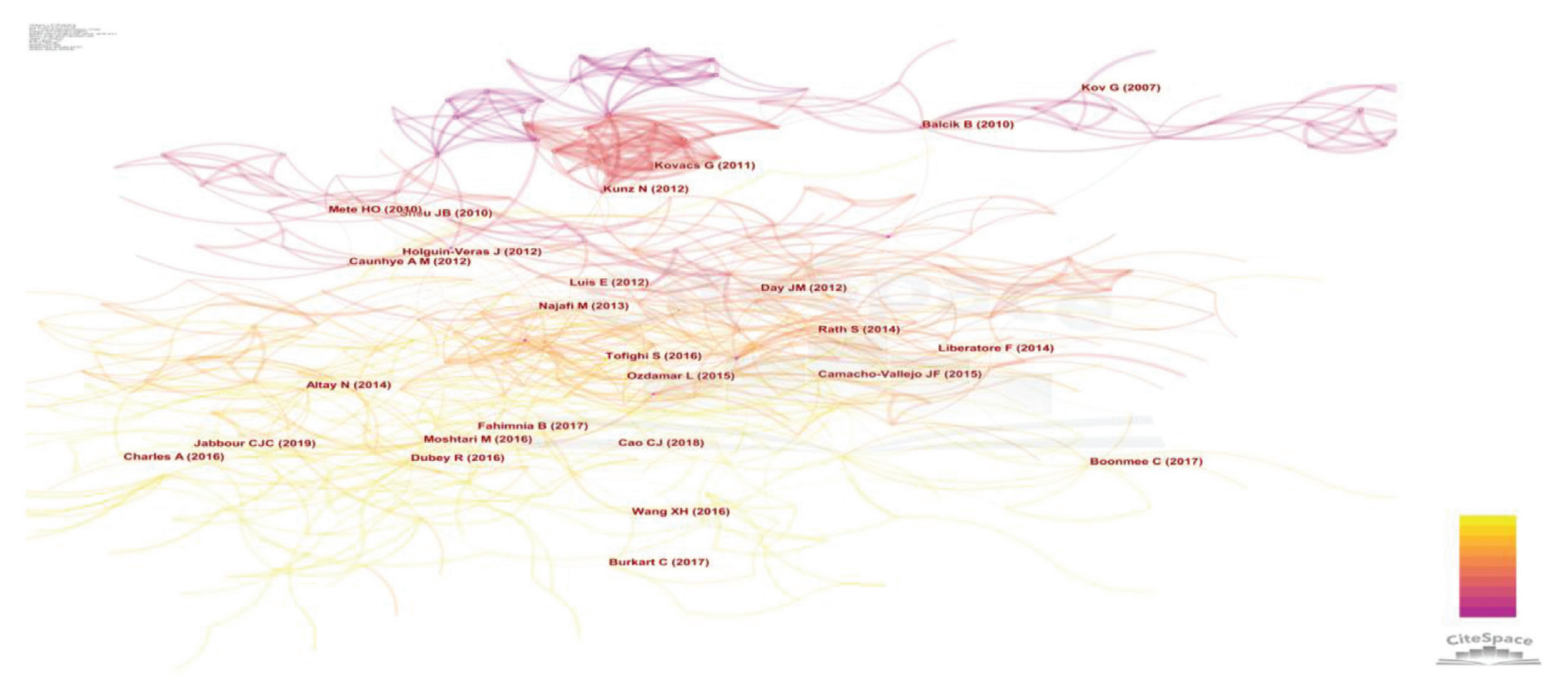

FIGURE 6: Network of co-cited references.

4.1. Factors Affecting Humanitarian Performance. Before discussing factors affecting humanitarian performance, this paper analyzes the difference between commercial logistics and HL in a holistic framework. Commercial logistics is mainly concentrated on the simulation of manufacturing, distribution, and waste recovery stage (Holguín-Veras et al. [18]), and the differences of HL as compared to commercial logistics are limited emergency resources, uncertainties, complex relations, and harderto-achieve efficient and timely delivery (Sheu [19]). According to emergency activities against the before or after emergency events, in this section, we focus on the main aspects when it comes to the contents of humanitarian management: mitigation, preparation, response, and recovery phases ( $\mathrm{Li}$ et al. [20]). Chen and Cui [21] divided the running proceeds of the virtual union into four stages, and operation models of HL virtual union for each stage were put forward.
Based on its research topics involving "The basic theory of HL, Risk assessment, Emergency monitoring, Early warning system, Emergency response, Guarantee, and Other practices" ( $\mathrm{Li}[22])$, this section mainly answers the following question: what are the impacting indexes affecting humanitarian performance? We summarize the relevant factors of each category in the analysis in Table 2, which can be classified into four categories by reading the collected reviews: information management capability, transportation and distribution capability, organization management capability, and recovery capability of HL. However, how to quantitatively analyze the complex factors impacting the service level of HL? Taking into account the potential challenge of collecting index data, some methodologies such as the critical success factor method and the fuzzy Delph and fuzzy DEMATEL method can be used. Zhou et al. [23] used the critical success factor method to carry out the five main factors for an emergency management system, such as the 


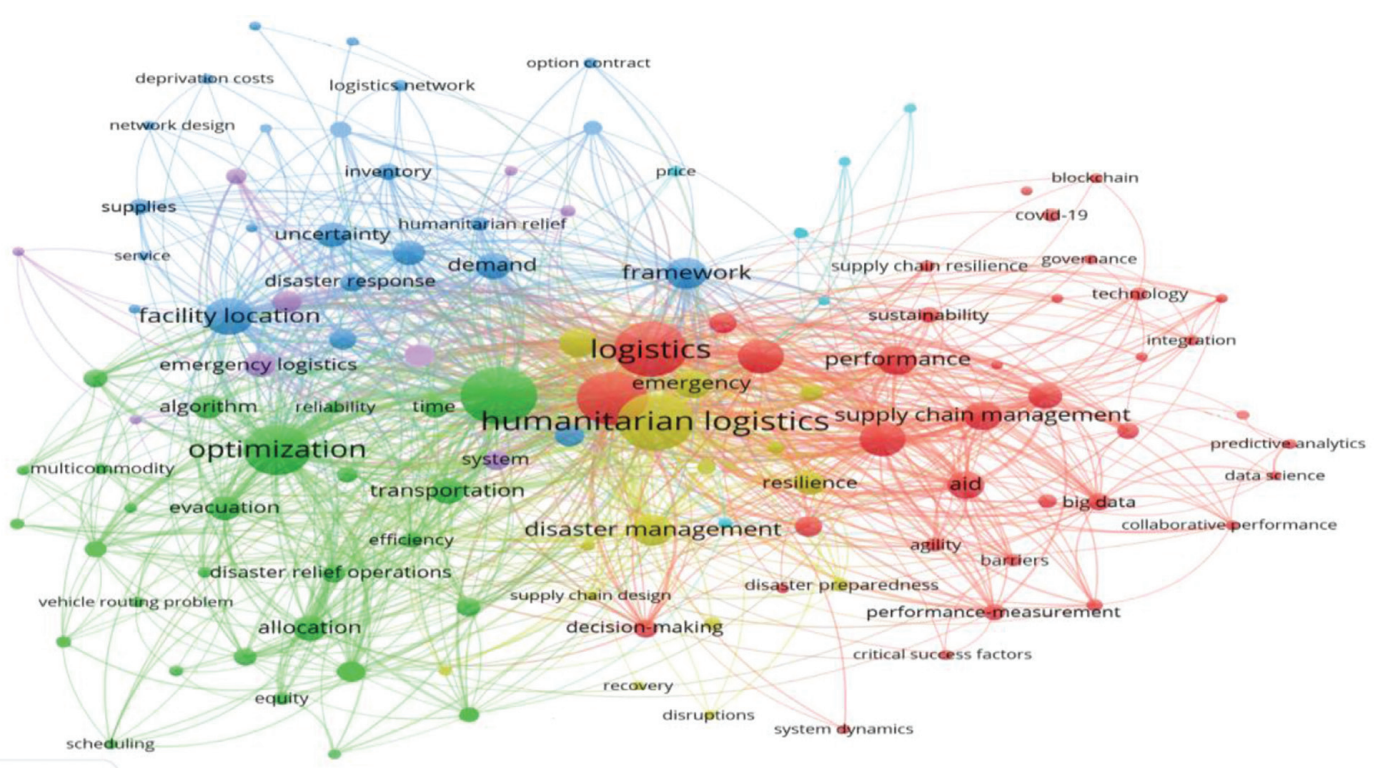

on vosviewer

Figure 7: Hot keyword label view of humanitarian logistics.

TABLE 2: Summary of the relevant factors for each category.

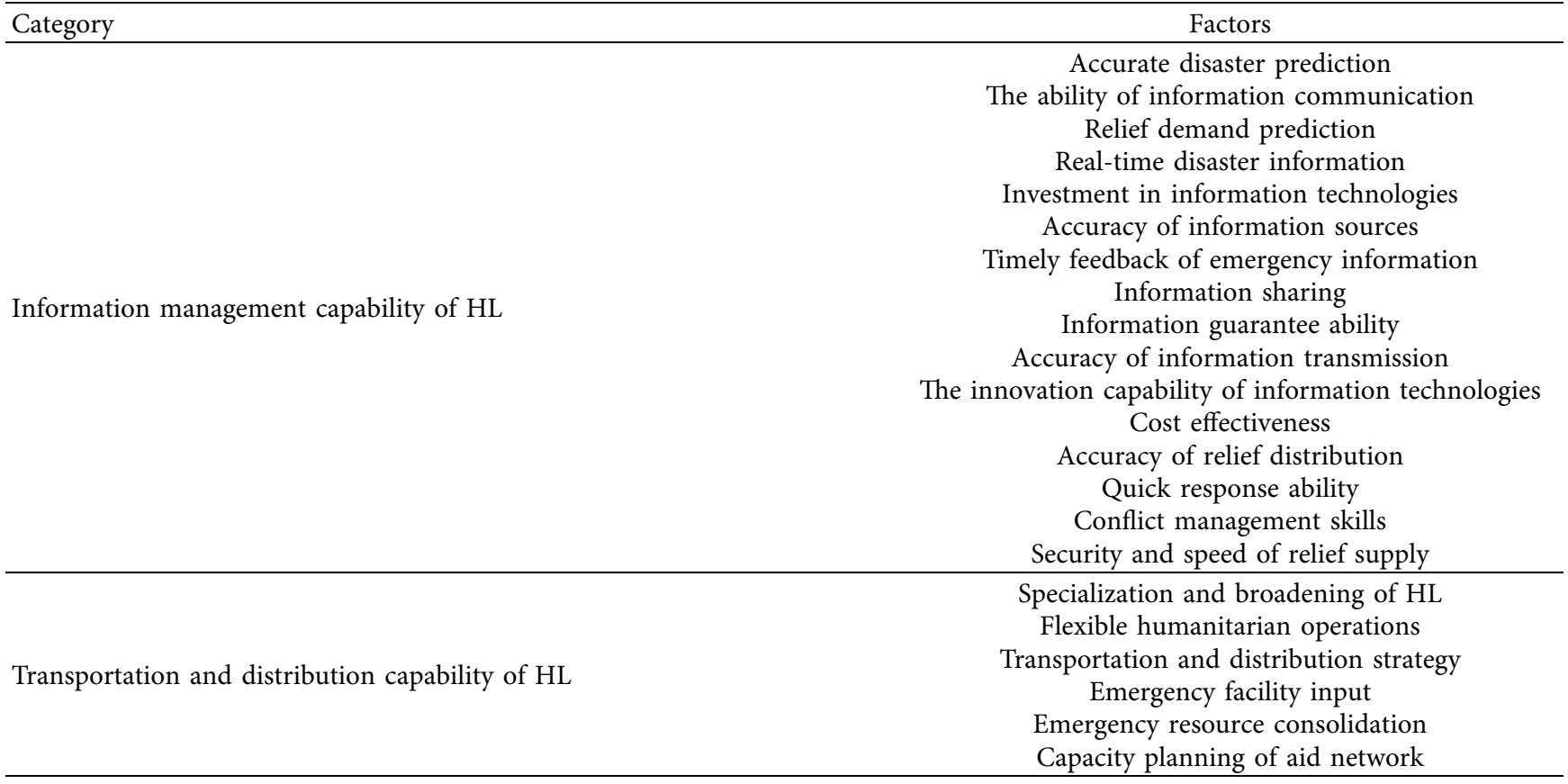


TABLE 2: Continued.

\begin{tabular}{lc}
\hline Category & Factors \\
\hline & Ethical behaviors and standards \\
Emergency talent training level & Coordination control capability \\
Investment in organization management & Linancial management of the humanitarian organization \\
Organization management capability of HL $\mathrm{HL}$ other organizations & Motivation and rewards \\
& Limitation of partners are understand \\
Organization communication ability & Reasonable organization structure \\
Emergency decision-making ability \\
Logistics network restoration \\
Economic recovery efficiency \\
Provision of emergency shelter \\
Supplies recycled \\
Recovery capability of HL & Investment in recycling management \\
& Safety and security of victims \\
& Number of people affected \\
Recycling mode choice \\
Recycling ability
\end{tabular}

reasonable organizational structure, effective emergency information system, government leadership, modern technologies, and continuous improvement.

4.2. Mathematical Models and Methodologies. The optimization of HL is viable enough to function well under the uncertain and complex nature of an emergency event. Scholars have conducted mathematical models and methodologies to increase the efficiency of HL. Before introducing the mathematical models, we need to clear up two things: emergency facility location and relief/casualty transportation. In the context of HL, the facilities are called emergency distribution centers, shelters, points of relief distribution, recovery centers, or other emergency facilities. The choice of emergency facility depends on the modes of transportation to be adopted. Boonmee et al. [24] provided a summary of facility location problems with HL. The needs of disaster sites cannot be met without relief/casualty transportation, which plays an instrumental role in protecting the affected people or casualties. Although casualty transportation plays a crucial role in sending the affected people to medical centers, there is no doubt that the vast majority of research focuses on relief transportation. Davis et al. [25] aimed at the situation of imminent disasters and constructed a random planning model of emergency relief location and distribution. Different categories of emergency facilities and modes of HL can form the emergency service network. A flexible and adaptable emergency network model involves a range of service actors. Dalal and Uater [26] combined the average cost and worst case in the second stage of emergency network design.

All kinds of complex network problems cannot be solved without mathematical models (deterministic and nondeterministic models), which have become a powerful tool to deal with the HL issues. The application scopes of mathematical modeling are very broad, including hurricanes, earthquakes, general, maritime disasters, and other scenarios. Moreover, models are mostly based on mixedinteger programs with binary location variables. Caunhye et al. [27] reviewed 74 articles about optimization models in disaster logistics, which were studied in terms of types of models, objectives, decisions, and constraints. Table 3 outlines the summary of mathematical models of HL from a multi-dimensional perspective.

As far as we know, some different methodologies such as mathematic algorithms, commercial software, or other approaches may be the adequate solution for mathematical models. A mathematical algorithm is used for combined optimization in which an optimal solution is sought over a discrete search space. Popular mathematical algorithms for combined problems include simulated annealing, tabu search, exact algorithm, and ant colony optimization [36]. Rennemo et al. [37] used a function of linear utility to search humanitarian aid distribution equity in a three-stage stochastic programming model for disaster response planning. $\mathrm{Ni}$ and Zhao [38] presented a Markov decision model to maximize lifesaving against an emergency medical resource allocation problem. In addition, commercial software has been updated and embedded with some common algorithms, which has become a powerful optimization platform. Table 4 illustrates the summary of mathematical models of HL.

It shows that more articles focus on the preparation and response phase of a disaster. The objectives of mathematical models are related to cost, time, relief shortage, and reliability, and the constraints of models usually include relief supply and vehicle, facility, inventory, and distance limit. Methodologies of models with complex constraints are mainly focusing on algorithms. However, according to the different models' requirements 
TABLE 3: Summary of mathematical models of HL (problem type, model, objective function, and stage of the disaster).

\begin{tabular}{|c|c|c|c|c|c|c|}
\hline \multirow[b]{2}{*}{ Authors } & \multicolumn{2}{|c|}{ Problem type } & \multicolumn{2}{|c|}{ Model } & \multirow[b]{2}{*}{ Objective function } & \multirow[b]{2}{*}{$\begin{array}{l}\text { Stage of the } \\
\text { disaster }\end{array}$} \\
\hline & $\begin{array}{c}\text { Emergency } \\
\text { facility } \\
\text { location } \\
\end{array}$ & $\begin{array}{l}\text { Relief/casualty } \\
\text { transportation }\end{array}$ & $\begin{array}{l}\text { Deterministic } \\
\text { model }\end{array}$ & $\begin{array}{l}\text { Nondeterministic } \\
\text { model }\end{array}$ & & \\
\hline Hu et al. [28] & $\sqrt{ }$ & & $\sqrt{ }$ & & $\begin{array}{l}\text { Minimize the cost and } \\
\text { evacuation distance }\end{array}$ & Preparation \\
\hline Wang et al. [29] & & $\sqrt{ }$ & $\sqrt{ }$ & & $\begin{array}{l}\text { Minimize the service time } \\
\text { and cost; maximize the } \\
\text { routing reliability }\end{array}$ & Response \\
\hline Ye et al. [30] & $\sqrt{ }$ & & $\sqrt{ }$ & & $\begin{array}{c}\text { Minimize the number of } \\
\text { warehouses for emergency } \\
\text { operation }\end{array}$ & Preparation \\
\hline $\begin{array}{l}\text { Rezaei-Malek } \\
\text { et al. [31] }\end{array}$ & $\sqrt{ }$ & & & $\sqrt{ }$ & $\begin{array}{l}\text { Minimize the cost and } \\
\text { response time }\end{array}$ & $\begin{array}{l}\text { Preparation, } \\
\text { response }\end{array}$ \\
\hline Amiri et al. [32] & $\sqrt{ }$ & & & $\sqrt{ }$ & $\begin{array}{l}\text { Minimize the maximum } \\
\text { amount of shortage and } \\
\text { predisaster and } \\
\text { postdisaster cost }\end{array}$ & $\begin{array}{l}\text { Preparation, } \\
\text { response }\end{array}$ \\
\hline Kinay et al. [33] & $\sqrt{ }$ & & & $\sqrt{ }$ & $\begin{array}{l}\text { Maximize minimum } \\
\text { weight of facilities }\end{array}$ & Preparation \\
\hline $\begin{array}{l}\text { Mohammadi } \\
\text { et al. [34] }\end{array}$ & $\sqrt{ }$ & & & $\sqrt{ }$ & $\begin{array}{c}\text { Minimize the total cost and } \\
\text { time }\end{array}$ & Response \\
\hline Li et al. [35] & & $\sqrt{ }$ & & $\sqrt{ }$ & Minimize the total cost & $\begin{array}{l}\text { Preparation, } \\
\text { response }\end{array}$ \\
\hline
\end{tabular}

TABle 4: Summary of mathematical models of HL (objectives, constraints, and methodologies).

\begin{tabular}{|c|c|c|c|c|c|c|c|c|}
\hline \multirow[b]{2}{*}{ Authors } & \multicolumn{4}{|c|}{ Objectives } & \multicolumn{3}{|c|}{ Constraints } & \multirow[b]{2}{*}{ Methodologies } \\
\hline & $\begin{array}{l}\text { Disaster } \\
\text { type }\end{array}$ & Cost & Time & Others & Capacity & $\begin{array}{c}\text { Requirements and } \\
\text { bounds }\end{array}$ & Others & \\
\hline Bayram et al. [39] & General & & $\sqrt{ }$ & & $\sqrt{ }$ & $\sqrt{ }$ & $\sqrt{ }$ & $\begin{array}{c}\text { Second-order cone programming } \\
\text { techniques }\end{array}$ \\
\hline $\begin{array}{l}\text { Bozorgi-Amiri } \\
\text { et al. [40] }\end{array}$ & Earthquakes & $\sqrt{ }$ & & $\sqrt{ }$ & $\sqrt{ }$ & & $\sqrt{ }$ & Exact algorithm \\
\hline $\begin{array}{l}\text { Afshar and } \\
\text { Haghani }[41]\end{array}$ & General & & & $\sqrt{ }$ & $\sqrt{ }$ & $\sqrt{ }$ & $\sqrt{ }$ & Exact algorithm \\
\hline $\begin{array}{l}\text { Abounacer et al. } \\
\text { [42] }\end{array}$ & General & & & $\sqrt{ }$ & $\sqrt{ }$ & $\sqrt{ }$ & $\sqrt{ }$ & $\begin{array}{l}\text { Exact pareto front, epsilon-constraint } \\
\text { method }\end{array}$ \\
\hline Duran et al. [43] & General & & $\sqrt{ }$ & & $\sqrt{ }$ & $\sqrt{ }$ & $\sqrt{ }$ & Exact algorithm \\
\hline Akgün et al. [44] & Earthquakes & & $\sqrt{ }$ & & $\sqrt{ }$ & & & Exact algorithm \\
\hline $\begin{array}{l}\text { Verma and } \\
\text { Gaukler [45] }\end{array}$ & Earthquakes & $\sqrt{ }$ & & & $\sqrt{ }$ & $\sqrt{ }$ & $\sqrt{ }$ & $\begin{array}{c}\text { Exact algorithm, sample average } \\
\text { approximation method }\end{array}$ \\
\hline $\begin{array}{l}\text { Salman and Yücel } \\
{[46]}\end{array}$ & Earthquakes & & & $\sqrt{ }$ & & $\sqrt{ }$ & $\sqrt{ }$ & Tabu search \\
\hline Hong et al. [47] & General & $\sqrt{ }$ & & & & $\sqrt{ }$ & & Exact algorithm \\
\hline Rennemo et al. [37] & General & $\sqrt{ }$ & & $\sqrt{ }$ & $\sqrt{ }$ & $\sqrt{ }$ & $\sqrt{ }$ & Stochastic programming \\
\hline
\end{tabular}

for different scenarios, more efficient models and approaches may be concerned in depth.

4.3. Humanitarian Supply Chain. Since this paper presents the state and affecting factors, mathematical models, and methodologies associated with $\mathrm{HL}$, the next step is to analyze the humanitarian supply chain (HSC). Considering the interconnection among HL and supply chain, numerous studies have been conducted on the topic of HSC, which can be regarded as a process of planning, controlling, and managing emergency information flows, reliefs, and services from the points of origin to the points of destination (Sheu [19]). It aims to ensure the living needs of victims and social stability by giving relief efficiently during and after the emergency event. Peng et al. [48] analyzed the behavior of disrupted supply chains under postdisaster conditions.

A list of preventing studies on HSC is provided in Table 5 . The relevant research involves "The basic theory of HSC, Mechanics of effective HSC, Optimization and coordination of HSC, Agility and resilience of HSC, and Critical success factors," which are consistent with the hot topics in Figure 7. Methodologies focus on the grey 
TABLE 5: Summary of humanitarian supply chain studies (criteria, problem, purpose, method, and key finding).

\begin{tabular}{|c|c|c|c|c|}
\hline Criteria & Problem(s) & Purpose(s) & Method(s) & Key finding(s) \\
\hline $\begin{array}{l}\text { Behl et al. } \\
\text { [49] }\end{array}$ & $\begin{array}{l}\text { How to find out the critical } \\
\text { factors for effective HSCM? }\end{array}$ & $\begin{array}{c}\text { Exploring the critical success factors } \\
\text { for implementation of effective } \\
\text { HSCM }\end{array}$ & $\begin{array}{l}\text { A grey DEMATEL } \\
\text { approach }\end{array}$ & $\begin{array}{l}\text { Proposing a conceptual model which } \\
\text { could be tested using empirical data }\end{array}$ \\
\hline $\begin{array}{l}\text { Singh et al. } \\
\text { [50] }\end{array}$ & $\begin{array}{l}\text { Which are the main factors } \\
\text { for resilient HSC? }\end{array}$ & $\begin{array}{l}\text { To identify the factors to develop } \\
\text { the resilience in HSC }\end{array}$ & $\begin{array}{c}\text { Fuzzy MICMAC } \\
\text { analysis }\end{array}$ & $\begin{array}{l}\text { Government support, strategy and } \\
\text { capacity planning, and continuous } \\
\text { assessment of project progress are } \\
\text { the major drivers for HSC }\end{array}$ \\
\hline $\begin{array}{l}\text { Dubey } \\
\text { et al. [51] }\end{array}$ & $\begin{array}{l}\text { Discussing the mechanics of } \\
\text { agility and resilience of HSC }\end{array}$ & $\begin{array}{l}\text { To establish the relationship } \\
\text { between agility, resilience, and } \\
\text { performance of HSC }\end{array}$ & Factor analysis & $\begin{array}{c}\text { Agility and resilience of HSC are two } \\
\text { determinants of the predisaster and } \\
\text { postdisaster supply chain } \\
\text { performance measures }\end{array}$ \\
\hline $\begin{array}{l}\text { Dubey } \\
\text { et al. [52] }\end{array}$ & $\begin{array}{l}\text { How to translate swift trust } \\
\text { into coordination of HSC } \\
\text { through commitment? }\end{array}$ & $\begin{array}{l}\text { To investigate empirically the role of } \\
\text { swift trust as mediating variable for } \\
\text { achieving supply chain } \\
\text { coordination }\end{array}$ & SEM & $\begin{array}{l}\text { Information sharing and behavioral } \\
\text { uncertainty reduction act as enablers } \\
\text { for swift trust, which is a missing link } \\
\text { for the success of HSC }\end{array}$ \\
\hline $\begin{array}{l}\text { Dasaklis } \\
\text { et al. [53] }\end{array}$ & $\begin{array}{l}\text { How to control the } \\
\text { infectious disease outbreak } \\
\text { by managing ESC? }\end{array}$ & $\begin{array}{c}\text { To effectively capture the disease's } \\
\text { dynamic with the perspective of } \\
\text { ESC }\end{array}$ & Simulation & $\begin{array}{l}\text { The proposed model and method can } \\
\text { serve as a sound operational } \\
\text { planning tool for healthcare } \\
\text { personnel as well as medical decision } \\
\text { makers }\end{array}$ \\
\hline $\begin{array}{l}\text { Yadav } \\
\text { et al. [54] }\end{array}$ & $\begin{array}{l}\text { How to search the critical } \\
\text { success factors of HSCM? }\end{array}$ & $\begin{array}{l}\text { To address the critical success } \\
\text { factors of HSC which emerges } \\
\text { during disaster preparedness and } \\
\text { immediate response phase }\end{array}$ & $\begin{array}{l}\text { Interpretive } \\
\text { structural } \\
\text { modeling }\end{array}$ & $\begin{array}{l}\text { Government policies and } \\
\text { organizational structure are the main } \\
\text { factors, while forming the base of } \\
\text { interpretive structural model }\end{array}$ \\
\hline $\begin{array}{l}\text { Mishra } \\
\text { et al. [55] }\end{array}$ & $\begin{array}{l}\text { How to reduce the wastage } \\
\text { of disaster relief materials of } \\
\text { HSC and enrich the related } \\
\text { research? }\end{array}$ & $\begin{array}{c}\text { To extend the dynamic capabilities } \\
\text { theory for lean thinking in HSC } \\
\text { management }\end{array}$ & $\begin{array}{l}\text { A qualitative } \\
\text { interpretative case } \\
\text { study }\end{array}$ & $\begin{array}{l}\text { Adapting the theory of constraints } \\
\text { and dynamic capabilities to know the } \\
\text { effective HSC management }\end{array}$ \\
\hline $\begin{array}{l}\text { Yadav } \\
\text { et al. [56] }\end{array}$ & $\begin{array}{l}\text { How to segment the critical } \\
\text { success factors of HSCM? }\end{array}$ & $\begin{array}{l}\text { To explore the critical success } \\
\text { factors of HSC in mitigating the } \\
\text { impact of cyclones in the Indian } \\
\text { context }\end{array}$ & $\begin{array}{l}\text { A grey DEMATEL } \\
\text { approach }\end{array}$ & $\begin{array}{c}\text { Out of } 16 \text { CSFs, ten CSFs have been } \\
\text { categorized into cause group CSFs } \\
\text { and six have been categorized into } \\
\text { the effect group CSFs }\end{array}$ \\
\hline
\end{tabular}

Note. HSC = humanitarian supply chain, HSCM = humanitarian supply chain management, ESC = emergency supply chain, fuzzy MICMAC analysis = fuzzy cross-impact matrix multiplication applied to classification analysis, a grey DEMATEL approach $=$ a grey decision-making trial and evaluation laboratory approach, SEM = structural equation modeling, and CSFs = critical success factors.

DEMATEL approach, fuzzy MICMAC analysis, interpretive structural modeling, and case study. Meanwhile, in order to solve the problems of HSC, such as the uncertain scenarios, unusual constraints, and unpredictable demand, the humanitarian network with multiple layers of notes and multiple agents of HSC can be constructed.

4.4. Applied Techniques and Means. Given the connection between HL and innovated techniques, numerous studies have regarded logistics techniques and means (e.g., computational method, surveillance system, real-time control and monitoring, remote sensing sensor, and so on) as a leading component in humanitarian management. Dubey et al. [57] analyzed the application of blockchain in enhancing collaboration among stakeholders engaged in disaster. The advancing techniques and means have been proposed as a potential solution for the organizational complexity and size asymmetry issues. Behl et al. [49] concluded that coordination and information sharing was a critical success factor for humanitarian operations. Technologies such as "Blockchain, Big data, and Data science" are used to reduce the risk and hazardous effects of "COVID-19,
Disaster, and Barriers," which are consistent with the content shown in Figure 7 . The applied techniques and means play a critical role in humanitarian management, while the use of it is good for reducing the destructive effect of disaster.

To provide a clearer picture of the hot knowledge of HL, based on the above analysis of four major categories of $\mathrm{HL}$, the research framework of hot topics in HL is summarized in Figure 8, which is the result of an integrated descriptive and exploratory analysis of the overview current state of HL. It demonstrates the process of taking actions (strategic planning and humanitarian operations) by some service agents in response to an emergency event. This context lays the foundation for Section 5 .

\section{Research Trend Analysis of Humanitarian Logistics}

Since this study intends to lay the ground for a systematic review of HL literature, this section investigates the potential tendency of $\mathrm{HL}$ over the next years. Because VOSviewer cannot present the changing laws of keywords with time, this paper applies CiteSpace to explore the 


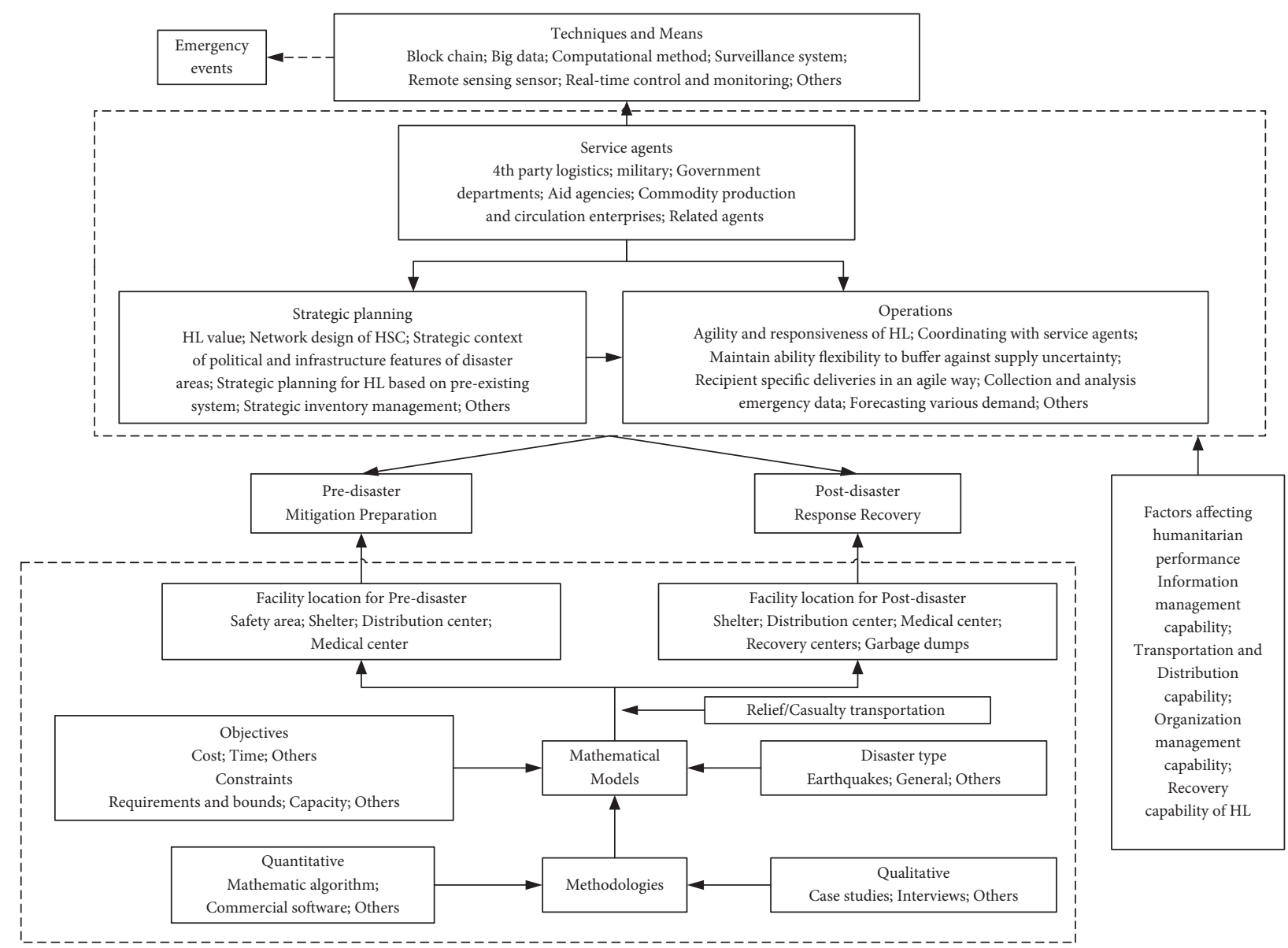

Figure 8: Research framework of hot topics in HL.

details of temporal relation change of HL through cocitation network analysis, and the result is outlined in Figure 9.

By analyzing the hot topics and changes of different keywords, the problems of "Emergency logistics, Emergency management, Humanitarian supply chain, Algorithm, Model, and Disaster preparedness" attracted scholars' attention as early as 2011, and their attention turned to "Disaster management, Performance measurement, Emergency logistics distribution, Network design, Big data, Critical success factor, Stochastic programming, Technology, Sustainability, Optimization model, and Option contract." The themes focus on "COVID-19, Blockchain, Last mile distribution, Location routing model, Relief distribution, Emergency supply, etc." since the later part of 2019.

As previously mentioned, the potential research directions of HL can be analyzed and classified. Meanwhile, this paper proposes some questions calling for future themes to address, as shown below.

First, researchers focus on discussing those topics, such as "Humanitarian relief, Emergency management, Distribution management, Emergency supply, Disaster management, Emergency logistics, and Disaster response" in Figure 9. Emergency management covers the different phases of an emergency event [20], which makes emergency management more effective the outsourcing engagements inevitably. Further analysis should be integrated with the important outsourcing theories (e.g., the resource-based view, transaction cost economics, and so on) using crosscase analysis of case studies to sufficiently specify the effect of HL and outsourcing decision making.

Furthermore, humanitarian performance should be viable to function well under the complex and uncertain nature. It is of great significance to evaluate which indexes can add value to the humanitarian operation. Considering that the service performance of HL is influenced by much more factors, such as institution, society, or individual behaviors, this paper calls for more studies to delve into the behavioral patterns and internal mechanisms and focuses on an evaluation indicator system based on the new theories. It is worth noting that lack of the data on some indexes is a common phenomenon. An integrated hybrid framework consists of mathematical modeling or simulation methods that may be applied to solve this problem in depth. Questions of interest include the following: 


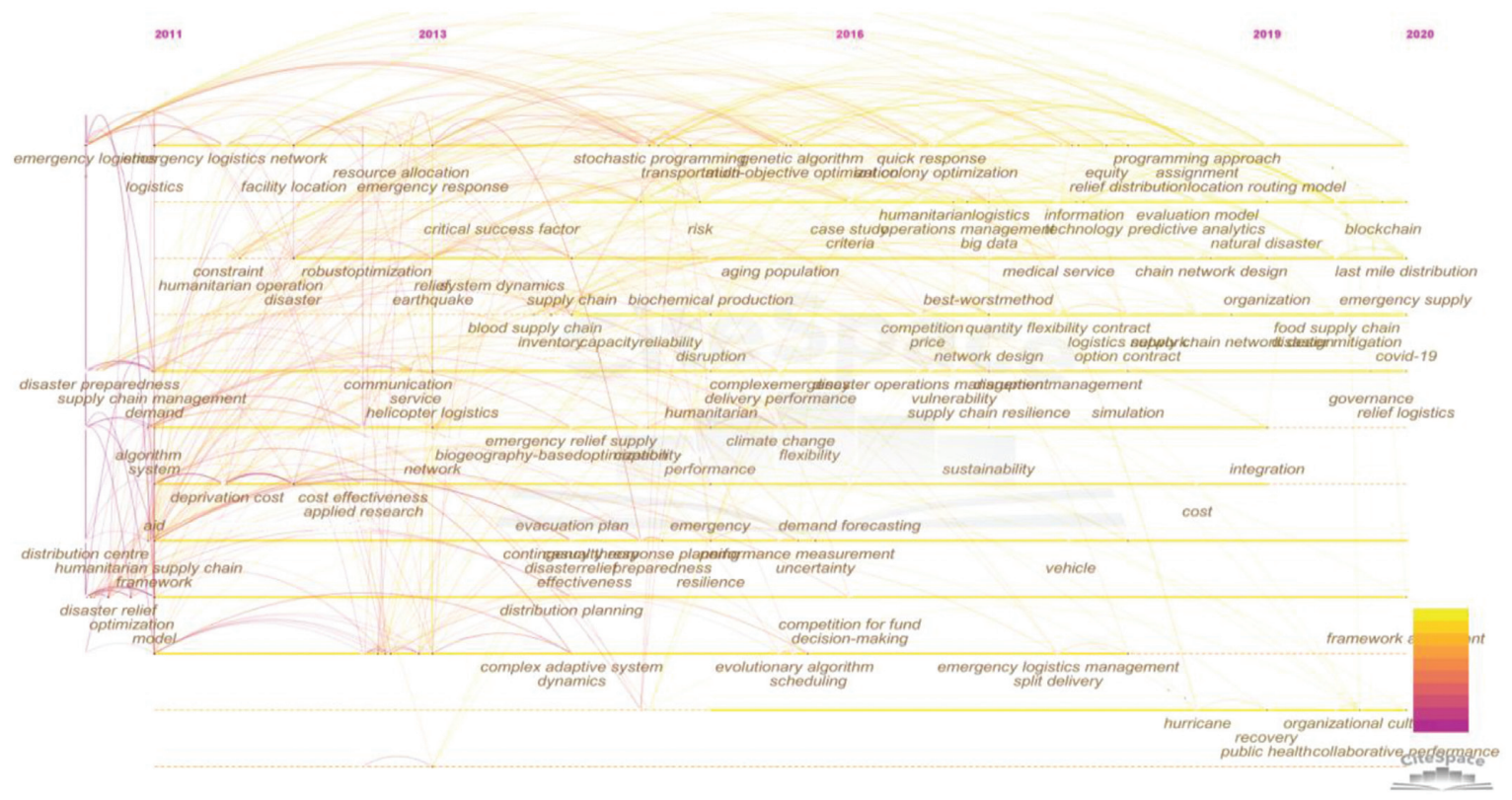

FIgURE 9: The merged network in timeline view.

Q1: what are the main factors that impact the service level of HL and the interdependencies among them?

Q2: how to construct an evaluation indicator system and which method can be adopted to assess system performance?

Second, Figure 9 displays that many studies have realized the relevant models of HL. The ways of "Stochastic programming, Robust optimization, Bi-objective optimization, Simulation, Predictive analytic, and Genetic algorithm" are applied to solve humanitarian problems, such as "Vehicle routing problem, Evacuation, Emergency supply, and Relief distribution." Meanwhile, the location routing model and optimization model are constructed with the objective of "Time window, Emergency cost, and Uncertainty." Further work cannot make implicit assumptions about humanitarian behaviors in an emergency environment. A realistic humanitarian model that contains some identified objections (e.g., cost, time, equity, satisfaction, and infection rate) could be constructed under the dynamic and uncertain disaster environment. Moreover, general characteristics of quantifying suffering for specific reliefs in demand nodes and emergency types can be discovered. As we all know, the more the objective functions of the humanitarian model, the more difficult it is to solve. In other words, the novel methodologies, tools, or more case-specific studies can be designed to solve a complex model, which is a multi-objective, multi-period, and stochastic model for the multi-relief problem.

Q3: how to build suitable models according to different scenarios (e.g., COVID-19, general, earthquake, and so on) and point out the similarities and differences among models?

Q4: what are the innovative methods and solutions to the different models or problems?
Third, as seen in Figure 9, the topics of "Humanitarian supply chain, Logistics network, Supply chain management, Disaster relief supply chain, and Chain network design" are usually aimed at "Sustainability, Agility, Flexibility, Efficiency, Equity, and Innovation." It can be noticed that means including "Blockchain, Big data, Information, and Technology" have a significant role in achieving the above goals. The innovative means and technologies are contributed to providing the decision support and optimal influencing strategies for HL and HSC. Of course, the implementation of technologies may have affected the HL and HSC. Therefore, two important research streams are strongly intertwined:

Q5: how to identify the potential barriers of logistics technologies for HL and HSC?

Q6: how to measure and overcome the influence of technological barriers?

In addition, the effective service of HL depends on an environment where multiple agents (such as 4th party logistics, military, and aid agencies) interact, but the conflicts of interest among service agents may negatively affect humanitarian performance, which can be attested by the point of view shifting to "Option contract and Contract." The interperiod incentive contract model commissioned by the government should be constructed. This model can also be analyzed to coordinate emergency service capacity and solve the actual profit problem between the government and enterprises. Furthermore, future research can focus on the game relationship, and synergetic mechanisms among agents are very important in coordinating humanitarian operations. Taking into consideration the context which involves multi-disciplinary research, from the economic and 


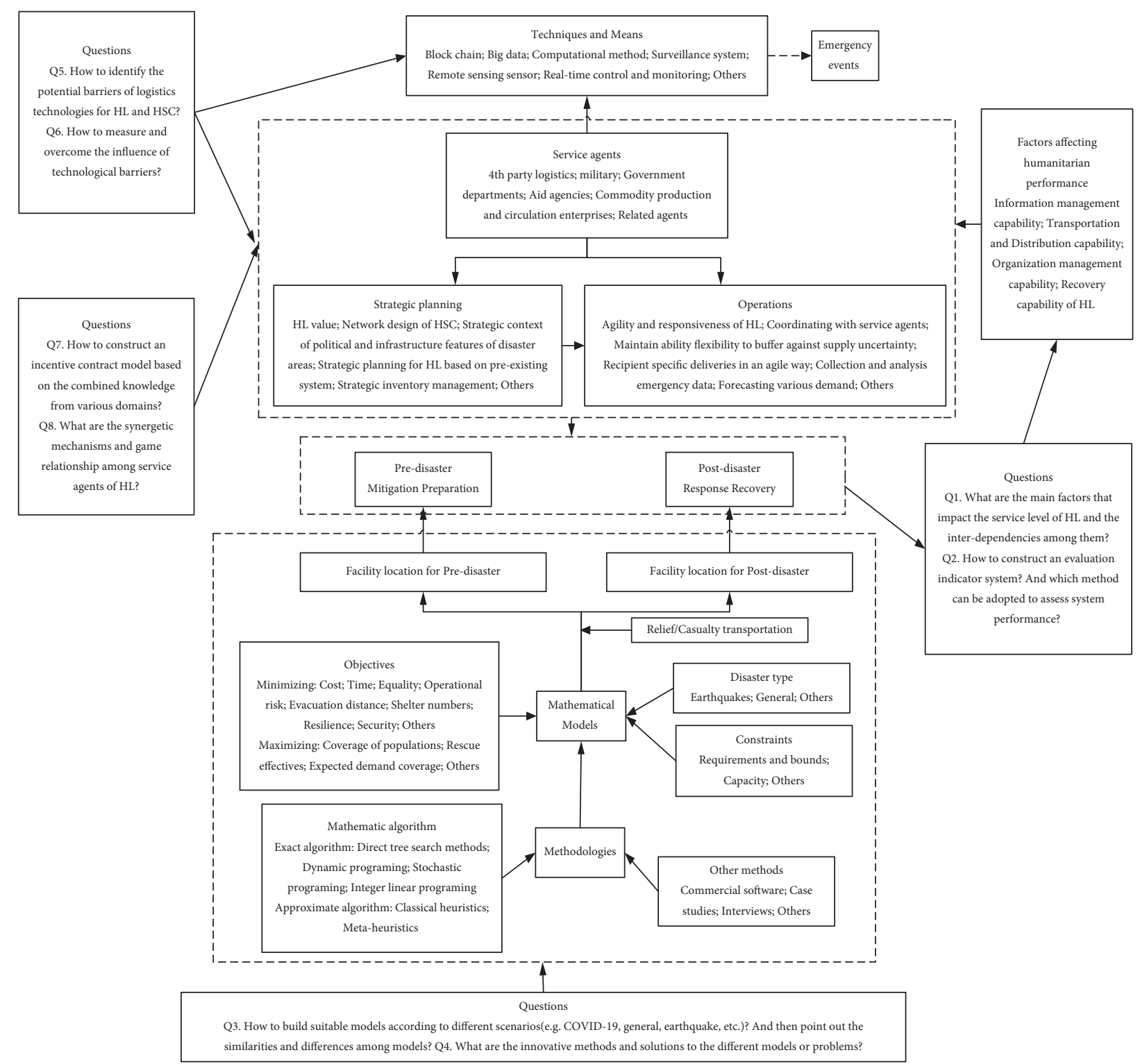

FIGURE 10: Framework and future research directions.

social point of view to a more analytical view, tools inherent to disaster psychology, game theory, system dynamics model, deep learning short-term memory method, the fuzzy best worst approach, and the multi-level programming may be conducive to addressing this problem.

Q7: how to construct an incentive contract model based on the combined knowledge from various domains?

Q8: what are the synergetic mechanisms and game relationships among service agents of HL?

To display the hot topics and research tendencies of HL, based on the analysis of Figures 8 and 9, the framework and future research direction of HL are shown in Figure 10, which reveals the hot topics, potential themes, and questions. In short, these research questions may catalyze new streams of the HL field. The above findings may provide valuable implications for the service agents of HL and facilitate the efficient development of HL.

\section{Conclusions and Suggestions}

The major work of this paper is to provide a comprehensive review of the research done on HL problems. Based on the systematic understanding of the intellectual structure and research topics of HL from 2011 to 2020, the potential research directions are identified under the bibliometric analysis method, the VOSviewer, and CiteSpace softwares. The corresponding conclusions and suggestions are as follows. 
Firstly, the theoretical nature of HL has attracted widespread attention, which can be attested by the annual document distribution curve. Although the group of authors has initially formed, the cooperative network of authors and countries shows a "partial concentration and overall dispersion" trend. Colleges and universities are in a dominant position with the strong scientific ability and academic atmosphere, but close contact and cooperation between different countries, institutions, and authors is lacking. To promote research quality in this field, the author teams from different institutions in different countries may need to strengthen contact and cooperation. They can also make attempts to expand the research scope of HL and explore the evolution of the coupling system of HL.

Secondly, keywords such as "Humanitarian logistics, Supply chain management, Logistics, Optimization, and Facility location" are uncovered based on the analysis of the label view, which illustrates that the scholars mostly study humanitarian problems from different perspectives. Based on the four major aspects proposed and investigated, this paper calls for government and enterprises to play an essential role in constructing a medical dispatch platform or an integrated emergency sharing platform. Meanwhile, the three-dimensional and full-covered emergency cooperation platform with unified information, resource sharing, and efficient operation is supposed to be constructed.

Finally, the multiobjective model and effective methodology, the interperiod incentive contract model, and an evaluation indicator system of HL may be the further work. The practice of HL also requires the diversification of service agents, the intelligence of service ways, and the quality of service process in HL. Therefore, service subjects can pay attention to establishing an integrated organization mechanism of HL. Moreover, an intelligent emergency material reserve mechanism is encouraged to be constructed to promote the integrated development of "physical reserve, contract reserve, production capacity reserve, and so on.”

To sum up, this study targets at contributing to the efforts of increasing a holistic knowledge on the domain of $\mathrm{HL}$, helping researchers to obtain more innovative perspectives, and providing valuable implications for the service agents of HL. However, there are limitations to the extant research. On the one hand, although WoS and Scopus are the most widely used databases in bibliometric review, it could be noted that some documents are not completely included. Moreover, the dataset is limited to journal articles, and some available reviews on HL may not have been captured. Future studies can broaden data sources drawn from various databases and take into consideration the potential references on HL, which may be more closer to the actual environment of HL. On the other hand, addressing the research topics of HL, more explanatory and prescriptive models can be built and applied.

\section{Data Availability}

The data used to support the findings of this study are available from the corresponding author upon request.

\section{Conflicts of Interest}

The authors declare that there are no conflicts of interest regarding the publication of this paper.

\section{References}

[1] L. N. Van Wassenhove, "Humanitarian aid logistics: supply chain management in high gear," Journal of the Operational Research Society, vol. 57, no. 5, pp. 475-489, 2006.

[2] Available online: https://coronavirus.jhu.edu/map.html.

[3] N. Altay and W. G. Green, "OR/MS research in disaster operations management," European Journal of Operational Research, vol. 175, no. 1, pp. 475-493, 2006.

[4] O. Ellegaard and J. A. Wallin, "The bibliometric analysis of scholarly production: how great is the impact?" Scientometrics, vol. 105, no. 3, pp. 1809-1831, 2015.

[5] A. Pritchard, "Statistical bibliography or bibliometrics," Journal of Documentation, vol. 25, no. 2, pp. 348-349, 1969.

[6] C. Chen, Z. Hu, S. Liu, and H. Tseng, "Emerging trends in regenerative medicine: a scientometric analysis in CiteSpace," Expert Opinion on Biological Therapy, vol. 12, no. 5, pp. 593-608, 2012.

[7] Y. Cui, J. Mou, and Y. Liu, "Knowledge mapping of social commerce research: a visual analysis using CiteSpace," Electronic Commerce Research, vol. 18, no. 4, pp. 1-32, 2018.

[8] N. J. Van Eck and L. Waltman, "Software survey: VOSviewer, a computer program for bibliometric mapping," Scientometrics, vol. 84, no. 2, pp. 523-538, 2010.

[9] A. Pilkington and J. Meredith, "The evolution of the intellectual structure of operations management-1980-2006: a citation/co-citation analysis," Journal of Operations Management, vol. 27, no. 3, pp. 185-202, 2009.

[10] É. Archambault, D. Campbell, Y. Gingras, and V. Larivière, "Comparing bibliometric statistics obtained from the Web of science and Scopus," Journal of the American Society for Information Science and Technology, vol. 60, no. 7, pp. 1320-1326, 2009.

[11] S. Seuring, S. Gold, and R. Wilding, "Conducting contentanalysis based literature reviews in supply chain management," Supply Chain Management: An International Journal, vol. 17, no. 5, pp. 544-555, 2012.

[12] Y. Chen, C. Chen, and Z. Y. Wang, "The methodology function of CiteSpace mapping knowledge domains," Studies in Science of Science, vol. 33, no. 2, pp. 242-253, 2015.

[13] M. J. Cobo, A. G. López-Herrera, E. Herrera-Viedma, and F. Herrera, "Science mapping software tools: review, analysis, and cooperative study among tools," Journal of the American Society for Information Science and Technology, vol. 62, no. 7, pp. 1382-1402, 2011.

[14] J. Zhu, L. J. Song, L. Zhu, and R. E. Johnson, "Visualizing the landscape and evolution of leadership research," The Leadership Quarterly, vol. 30, pp. 215-232, 2018.

[15] F. García-Lillo, M. Úbeda-García, and B. Marco-Lajara, "The intellectual structure of research in hospitality management: a literature review using bibliometric methods of the journal International Journal of Hospitality Management," International Journal of Hospitality Management, vol. 52, pp. 121-130, 2016.

[16] H. Zhao, C. Niu, T. Zhang, and S. Cai, "Review and prospect of emergency logistics under uncertainty conditions," Journal of Risk Analysis and Crisis Response, vol. 8, no. 2, p. 101, 2018.

[17] S. Tofighi, S. A. Torabi, and S. A. Mansouri, "Humanitarian logistics network design under mixed uncertainty," European 
Journal of Operational Research, vol. 250, no. 1, pp. 239-250, 2016.

[18] J. Holguín-Veras, M. Jaller, L. N. Van Wassenhove, N. Pérez, and T. Wachtendorf, "On the unique features of post-disaster humanitarian logistics," Journal of Operations Management, vol. 30, no. 8, pp. 494-506, 2012.

[19] J.-B. Sheu, "Challenges of emergency logistics management," Transportation Research Part E: Logistics and Transportation Review, vol. 43, no. 6, pp. 655-659, 2007.

[20] Q. Li, W. Tu, and L. Zhuo, "Reliable rescue routing optimization for urban emergency logistics under travel time uncertainty," ISPRS International Journal of Geo-Information, vol. 7, no. 2, pp. 77-78, 2018.

[21] W. K. Chen and H. Cui, "Research on operation models of emergency logistics virtual union based on emergency lifecycle," Journal of Catastrophology, vol. 30, pp. 152-157, 2015.

[22] H. Q. Li, "Visualization analysis of emergency management in China based on knowledge mapping (2010-2014)," Journal of Modern Information, vol. 1, pp. 160-166, 2016.

[23] Q. Zhou, W. Huang, and Y. Zhang, "Identifying critical success factors in emergency management using a fuzzy DEMATEL method," Safety Science, vol. 49, no. 2, pp. 243-252, 2011.

[24] C. Boonmee, M. Arimura, and T. Asada, "Facility location optimization model for emergency humanitarian logistics," International Journal of Disaster Risk Reduction, vol. 24, pp. 485-498, 2017.

[25] L. B. Davis, F. Samanlioglu, X. Qu, and S. Root, "Inventory planning and coordination in disaster relief efforts," International Journal of Production Economics, vol. 141, no. 2, pp. 561-573, 2013.

[26] J. Dalal and H. Uater, "Combining worst case and average case considerations in an integrated emergency response network design problem," Transportation Science, vol. 51, no. 1, pp. $60-165,2017$.

[27] A. M. Caunhye, X. Nie, and S. Pokharel, "Optimization models in emergency logistics: a literature review," SocioEconomic Planning Sciences, vol. 46, no. 1, pp. 4-13, 2012.

[28] F. Hu, S. Yang, and W. Xu, "A non-dominated sorting genetic algorithm for the location and districting planning of earthquake shelters," International Journal of Geographical Information Science, vol. 28, no. 7, pp. 1482-1501, 2014.

[29] H. Wang, L. Du, and S. Ma, "Multi-objective open locationrouting model with split delivery for optimized relief distribution in post-earthquake," Transportation Research Part E: Logistics and Transportation Review, vol. 69, pp. 160-179, 2014.

[30] F. Ye, Q. Zhao, M. Xi, and M. Dessouky, "Chinese national emergency warehouse location research based on VNS algorithm," Electronic Notes in Discrete Mathematics, vol. 47, pp. 61-68, 2015.

[31] M. Rezaei-Malek, R. Tavakkoli-Moghaddam, B. Zahiri, and A. Bozorgi-Amiri, "An interactive approach for designing a robust disaster relief logistics network with perishable commodities," Computers \& Industrial Engineering, vol. 94, pp. 201-215, 2016.

[32] A. Bozorgi-Amiri and M. Khorsi, “A dynamic multi-objective location-routing model for relief logistic planning under uncertainty on demand, travel time, and cost parameters," The International Journal of Advanced Manufacturing Technology, vol. 85, no. 5-8, pp. 1633-1648, 2016.

[33] Ö. B. Kinay, B. Y. Kara, F. Saldanha-da-Gama, and I. Correia, "Modeling the shelter site location problem using chance constraints: a case study for Instanbul," European Journal of Operational Research, vol. 270, pp. 132-145, 2018.

[34] S. Mohammadi, S. Avakh, B. Vahdani, and A. Alinezhad, "A robust neutrosophic fuzzy-based approach to integrate reliable facility location and routing decision for disaster relief under fairness and aftershocks concern," Computers and Industrial Engineering, vol. 148, pp. 106-734, 2020.

[35] Y. Li, G. Yu, and J. Zhang, "A three-stage stochastic model for emergency relief planning considering secondary disaster," Engineering Optimization, vol. 53, pp. 1-15, 2021.

[36] X. S. Yang, Introduction to Mathematical Optimization: From Linear Programming to Metaheuristics, Cambridge International Science Publishing, Cambridge, UK, 2008.

[37] S. J. Rennemo, K. F. Ro, L. M. Hvattum, and G. Tirado, "A three-stage stochastic facility routing model for disaster response planning," Transportation Research Part E: Logistics and Transportation Review, vol. 62, pp. 116-135, 2014.

[38] Y. Ni and L. Zhao, "A Markov decision process model for allocation emergency medical resource among multi-priority injuries," International Journal of Mathematics in Operational Research, vol. 10, no. 1, pp. 1-17, 2014.

[39] V. Bayram, B. Ç. Tansel, and H. Yaman, "Compromising system and user interests in shelter location and evacuation planning," Transportation Research Part B: Methodological, vol. 72, pp. 146-163, 2015.

[40] A. Bozorgi-Amiri, M. S. Jabalameli, and S. M. J. Mirzapour Ale-Hashem, "A multi-objective robust stochastic programming model for disaster relief logistics under uncertainty," $O R$ Spectrum, vol. 35, no. 4, pp. 905-933, 2013.

[41] A. Afshar and A. Haghani, "Modeling integrated supply chain logistics in real-time large-scale disaster relief operations," Socio-Economic Planning Sciences, vol. 46, no. 4, pp. 327-338, 2012.

[42] R. Abounacer, M. Rekik, and J. Renaud, "An exact solution approach for multi-objective location-transportation problem for disaster response," Computers and Operations Research, vol. 41, pp. 83-93, 2014.

[43] S. Duran, M. A. Gutierrez, and P. Keskinocak, "Pre-positioning of emergency items for CARE international," Interfaces, vol. 41, no. 3, pp. 223-237, 2011.

[44] İ. Akgün, F. Gümüşbuğa, and B. Tansel, "Risk based facility location by using fault tree analysis in disaster management," Omega, vol. 52, pp. 168-179, 2015.

[45] A. Verma and G. M. Gaukler, "Pre-positioning disaster response facilities at safe locations: an evaluation of deterministic and stochastic modeling approaches," Computers and Operations Research, vol. 62, pp. 197-209, 2015.

[46] F. S. Salman and E. Yücel, "Emergency facility location under random network damage: insights from the Istanbul case," Computers and Operations Research, vol. 62, pp. 266-281, 2015.

[47] J. D. Hong, Y. Xie, and K. Y. Jeong, "Development and evaluation of an integrated emergency response facility location model," Journal of Industrial Engineering and Management, vol. 5, no. 1, p. 4, 2012.

[48] M. Peng, Y. Peng, and H. Chen, "Post-seismic supply chain risk management: a system dynamics disruption analysis approach for inventory and logistics planning," Computers and Operations Research, vol. 42, pp. 14-24, 2014.

[49] A. Behl, P. Dutta, and S. Gupta, "Critical success factors for humanitarian supply chain management: a grey DEMATEL approach," IFAC-PapersOnline, vol. 2442, no. 13, pp. 159-164, 2020. 
[50] R. K. Singh, A. Gupta, and A. Gunasekaran, "Analysing the interaction of factors for resilient humanitarian supply chain," International Journal of Production Research, vol. 56, no. 21, pp. 6809-6827, 2018.

[51] R. Dubey, S. S. Ali, P. Aital, and V. G. Venkatesh, "Mechanics of humanitarian supply chain agility and resilience and its empirical validation," International Journal of Services and Operations Management, vol. 17, no. 4, pp. 367-384, 2014.

[52] R. Dubey, N. Altay, and C. Blome, "Swift trust and commitment: the missing links for humanitarian supply chain coordination?" Annals of Operations Research, vol. 283, no. 1-2, pp. 159-177, 2019.

[53] T. K. Dasaklis, N. Rachaniotis, and C. Pappis, "Emergency supply chain management for controlling a smallpox outbreak: the case for regional mass vaccination," International Journal of Systems Science: Operations and Logistics, vol. 4, no. 1, pp. 27-40, 2017.

[54] D. K. Yadav and A. Barve, "Analysis of critical success factors of humanitarian supply chain: an application of Interpretive Structural Modeling," International Journal of Disaster Risk Reduction, vol. 12, pp. 213-225, 2015.

[55] J. L. Mishra, K. D. Chiwenga, N. Mishra, and S. Choudhary, "Extending dynamic capabilities toward lean thinking in humanitarian supply chains," Production Planning and Control, vol. 23, no. 1, pp. 183-185, 2020.

[56] D. K. Yadav and A. Barve, "Segmenting critical success factors of humanitarian supply chains using fuzzy DEMATEL," Benchmarking: An International Journal, vol. 25, no. 2, pp. $400-425,2018$.

[57] R. Dubey, A. Gunasekaran, D. J. Bryde, Y. K. Dwivedi, and T. Papadopoulos, "Blockchain technology for enhancing swift-trust, collaboration and resilience within a humanitarian supply chain setting," International Journal of Production Research, vol. 58, no. 11, pp. 3381-3398, 2020. 